\title{
Selection of a Monetary Aggregate For Economic Stabilization
}

\author{
LEONALL C. ANDERSEN
}

I $\mathrm{N}$ recent years there has been growing acceptance of the view that controlling the growth of monetary aggregates is a useful strategy for purposes of economic stabilization. In particular, it is argued that the probability of achieving the desired growth of nominal gross national product (also referred to as income) can be improved by controlling growth of the monetary aggregates. Thus, assuming that in the long run real GNP grows at a constant rate determined by growth of the labor force and productivity, then controlling the long-run growth of nominal GNP would be an effective means of controlling the rate of inflation.

Monetary aggregates consist of various combinations of short-term, highly liquid, financial assets held by the private sector. Exhibit I defines seven of the most prominently mentioned measures. The aggregates labeled $\mathrm{M}_{1}$ through $\mathrm{M}_{4}$ have been viewed by various analysts as constituting a temporary abode of purchasing power or as a means for carrying out transactions. The monetary base is generally viewed as both the dominant factor determining $\mathrm{M}_{1}$ and $\mathrm{M}_{2}$ and as being under direct control of the Federal Reserve System. Since $M_{2}$ constitutes a major portion of $\mathrm{M}_{3}$ through $\mathrm{M}_{6}$, the monetary base is a major factor affecting these aggregates, but the relationship is not as close.

Accepting this monetary aggregate view for the conduct of economic stabilization policy, there remains the question of which one of the monetary aggregates has the most predictable effect on nominal GNP. One generally accepted criterion for selecting a monetary aggregate is to choose the one which produces the smallest error in forecasting nominal GNP. Another criterion is to choose the aggregate over

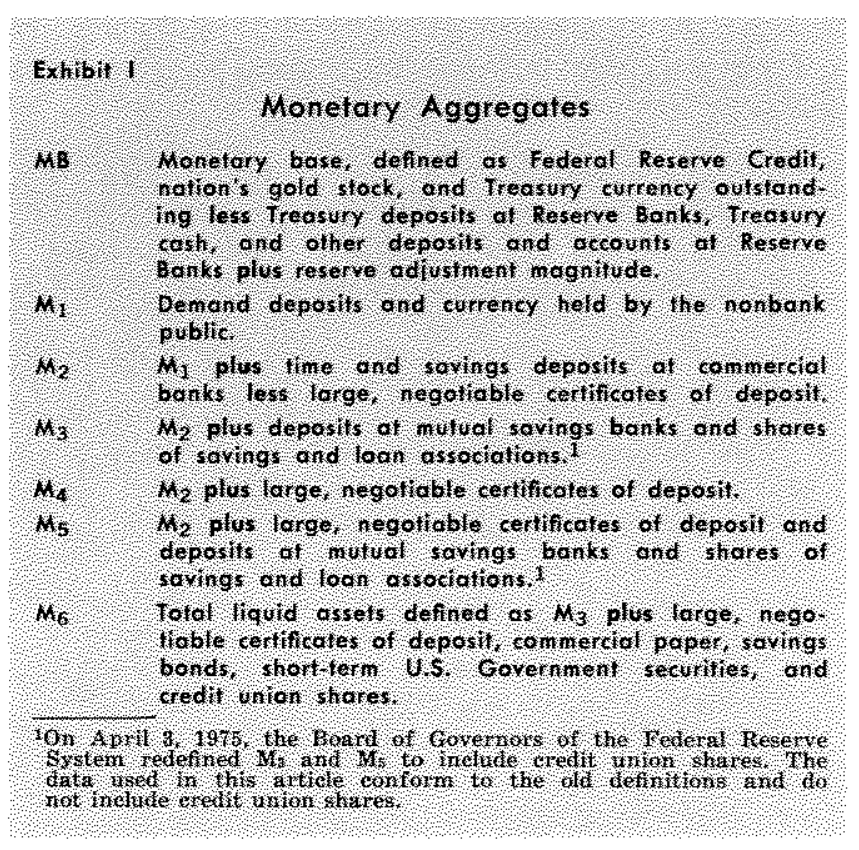

which monetary authorities have the best control. In making the ultimate selection, both criteria would have to be considered; this article, however, is concerned only with the first one - forecasting.

Two approaches have been used in this regard. One examines the relative stabilities among the various ratios of GNP to each aggregate, referred to as income velocities. This indirect approach asserts that the aggregate which has the smallest variability in its income velocity can be expected to forecast nominal GNP with the smallest error. The other approach uses a model of nominal GNP determination. In this approach, forecasts of nominal GNP are made using various aggregates, and the one which forecasts with the smallest error is directly ascertained. 


\section{TNDITECT VELOCITY APPROACH}

Milton Friedman, using the indirect velocity approach, has argued the case for choosing $M_{2}$ over $\mathbf{M}_{1}$ as the appropriate monetary aggregate for economic stabilization. ${ }^{1}$ His analysis runs as follows:

It is a tantology, or identity, that Growth Rate of Nominal Income $=$ Growth Rate of Money plus Growth Rate of Velocity, provided that velocity is defined consistently with whatever concept of money is employed.

If velocity (defined as income divided by the quantity of money) were a 'will-of-the-wisp' that fluctuated all over the lot in an unpredictable fashion - as the naive Keynesians initially asserted this tautology would be of no use. However, velocity is not a 'will-of-the-wisp.' It behaves in a consistent and fairly predictable way.

Friedman then analyzed the period from 1948 to 1972:

... the velocity of $M_{1}$ has had a decided upward trend throughout the period, though with a sharp deceleration after 1966, and a suspicious acceleration in 1972. Using $M_{1}$ to judge desired monetary growth requires forecasting the likely secular growth in its velocity, and we have no very satisfactory basis for doing so.

The velocity of $\mathrm{M}_{2}$ had a more moderate upward trend before 1962 , but has displayed no appreciable trend in either direction since. It has been extraordinarily stable. Of the 44 quatterly values for the years 1962 through 1972 , the highest is 2.43 , the lowest, 2.29 a difference from high to low of $6 \%$, or $\pm 3 \%$ about the mean value of 2.36 . In striking contrast, the velocity of $\mathrm{M}_{1}$ went from 2.19 in 1962 to 4.72 in 1972 .

On the basis of this analysis, he concluded:

The greater stability [long-run] of the velocity of $M_{2}$ than of the velocity of $M_{1}$ suggests that it is safer to specify monetary objectives in terms of $M_{2}$ than in terms of $M_{1}$, since doing so requires no allowance for an uncertain secular trend in velocity.

Friedman then observed:

The advantage of no trend might be offset if the velocity of $\mathrm{M}_{2}$ were more variable over short periods than the velocity of $M_{1}$ after allowance for trend. But this is not the case. Numerous studies we have made for recent years and also for the whole period since 1914 (when reliable estimates of $\mathrm{M}_{1}$ first became available) demonstrate that, if anything, the

Milton Friedman, "How Much Monetary Growth," The Molgan Guaranty Survey (February 1973), pp. 5-10. velocity of $M_{2}$ is less variable over short periods than the velocity of $\mathrm{M}_{1}$.

Of course, there is no guarantee that the velocity of $\mathrm{M}_{3}$ will not depart from its recent relatively constant level, but neither theory nor the past historical behavior of the velocity of $\mathrm{M}_{2}$ gives any reason to expect a sudden or large departure.

\section{Longrun Variability of Velocity}

The long-run variability of velocity is ascertained by examining movements in the level of velocity over long periods of time. The accompanying chart presents the ratio of nominal GNP to each monetary aggregate for the period 1952-1973.2 The beginning date was selected to eliminate the period of the Federal Reserve/Treasury Accord, which was included in Friedman's analysis of $\mathrm{M}_{1}$ and $\mathrm{M}_{2}$ velocities.

An examination of the chart indicates that $V_{m b}$ and $V_{1}$ both have pronounced upward trends over the whole period, but that a break in their trends occurred after the fourth quarter of 1966 (Table I). The trend of $V_{\mathrm{mal}}$ changed from an average 3.0 percent annual rate to an average 1.8 percent rate, and the trend of $V_{1}$ changed from an average 3.2 percent annual rate to an average 1.8 percent rate. While over the whole period the trend growths of $V_{2}$ and $V_{4}$ are much less than those of $V_{m b}$ and $V_{1}$, a break in their trends also occurred (Table I). $V_{2}$ grew at an average 1.2 percent annual rate to the fourth quarter of 1961, and then remained unchanged through fourth quarter $1973 . V_{4}$ grew at an average 1.1 percent annual rate to the end of 1961, and subsequently decreased at an average 0.8 percent annual rate. Income velocities $V_{3}, V_{5}$ and $V_{6}$ have slightly negative trend growth rates with no discernable breaks.

Two statistical measures of variability of a time series are the standard deviation and the coefficient of variation, which is the ratio of the standard deviation to the mean. This latter measure allows a comparison of the variability of series which have different magnitudes. The larger the values of these measures, the greater is the variability of the series.

Table II presents the long-run variability of these velocity measures for the period 1952 to 1973 . According to the coefficients of variation the levels of $V_{\text {min }}$ and $V_{I}$ have, by far, the greatest variability for the whole period. The velocity measure with the smallest variability in its level for the whole period is $V_{t}$.

\footnotetext{
Except for GNP divided by $\mathrm{M}_{3}$ and $\mathrm{M}_{5}$; data for $\mathrm{M}_{3}$ and $\mathrm{M}_{5}$ are avalable only from the second quarter of 1955.
} 


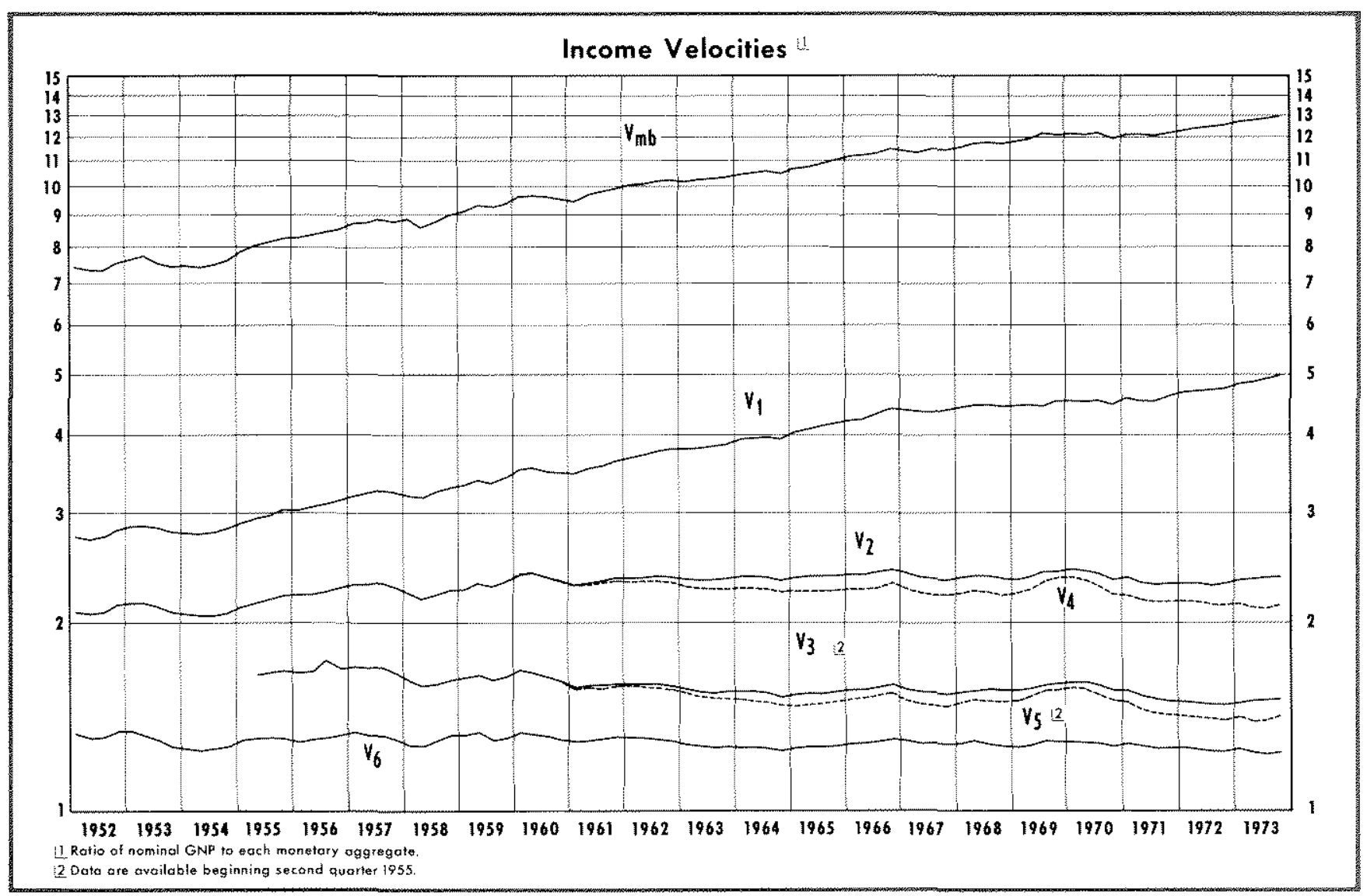

When consideration is given to the changes in the trends of four of the velocity measures the relative rankings of long-run variability are little changed. In the period before the various breaks in the trends, $V_{6}$ had the smallest long-run variability and $V_{m b}$ and $V_{1}$ the largest. After the break in trend, $V_{22}$ had the smallest long-run variability.

The preceding analysis of long-run variability in the levels of various measures of income velocity is misleading because the coefficients of variation are greatly influenced by the existence of trend move-

\begin{tabular}{|c|c|c|c|c|c|}
\hline \multirow[b]{2}{*}{ Velocity } & \multirow[b]{2}{*}{$1 / 95210$} & \multicolumn{4}{|c|}{$\begin{array}{ll}\text { lelocity Growth Selected Periods } \\
\text { rompounsed annual Rofes }\end{array}$} \\
\hline & & Dolse & Growth & Dates & Growth \\
\hline Yorte & $2 . \%$ & $1 / 52101466$ & $3.0 \%$ & $14 / 66$ fo $\mathrm{N} / \mathrm{s}$ & $18 \%$ \\
\hline $\mathrm{v}_{1}$ & 20 & 181014160 & 32 & $\mathrm{~W} / 6610 \mathrm{~W} / 73$ & 16 \\
\hline $\mathrm{r}_{2}$ & 06 & $1 / 51 / 0 / 1 / 61$ & 12 & $\mathrm{~N} / 61 \mathrm{or} \mathrm{N} / \mathrm{s}$ & 00 \\
\hline $\mathrm{v}$ ? & 05 & 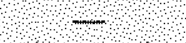 & 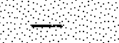 & 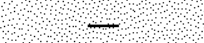 & $?$ \\
\hline$y_{4}$ & 01 & $1 / 52$ o $1 \mathrm{v} / 61$ & 1 & $1 \times / 6101 \times 173$ & 0,8 \\
\hline$Y_{5}$ & 08 & 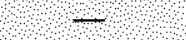 & 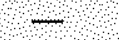 & 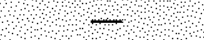 & 1 \\
\hline$y_{6}$ & 0.3 & 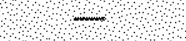 & 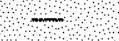 & ? & 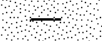 \\
\hline
\end{tabular}

ments. A measure of velocity with a pronounced trend will have a larger coefficient of variation (the ratio of its standard deviation to its mean) than a measure of velocity with no trend. A more appropriate procedure is to eliminate the trend from the data. The analysis in the next section takes this adjustment into consideration.

\section{Short-run Variability of Velocity}

The short-run variability of a measure of velocity is analyzed by using quarter-to-quarter percent changes (at annual rates) and the moving average of these changes over four quarters and eight quarters. The two periods for averaging are selected on the basis of frequently proposed time horizons for economic stabilization. The standard deviations of these three types of change are used as comparative measures of short-run variability. Since the standard deviation measures variability around the mean and since the mean, in the case of percent changes, is the average growth rate, the standard deviation is a measure of the variability 


\begin{tabular}{|c|c|c|c|c|c|c|}
\hline \multirow[b]{2}{*}{$\begin{array}{l}\text { Yelocity } \\
\text { Measure }\end{array}$} & \multicolumn{4}{|c|}{ 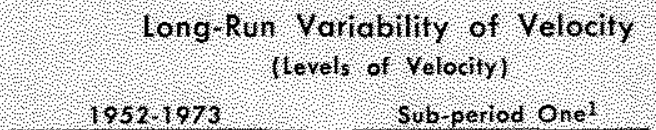 } & \multicolumn{2}{|c|}{ Sub reoriod ruol } \\
\hline & $\begin{array}{l}\text { storodord } \\
\text { Derlotor }\end{array}$ & $\begin{array}{l}\text { Coeficient } \\
\text { of Voliatron }\end{array}$ & $\begin{array}{l}\text { stondard } \\
\text { Devigtion }\end{array}$ & $\begin{array}{l}\text { Coefficrent } \\
\text { of Voriolion }\end{array}$ & $\begin{array}{l}\text { stororord } \\
\text { beriotoli }\end{array}$ & $\begin{array}{l}\text { coeffiront } \\
\text { of Vorrotion }\end{array}$ \\
\hline$Y_{\text {rata }}$ & 16097 & 167 & 1,217 & 132 & 438 & 036 \\
\hline Y & 675 & 178 & 476 & 139 & 170 & 037 \\
\hline$v_{2}$ & 101 & 1044 & 102 & 0.46 & 1032 & 014 \\
\hline$v_{3}$ & 057 & 036 & .057 & 036 & 857 & 036 \\
\hline 4 & 084 & 038 & 1001 & 045 & 066 & 029 \\
\hline$y_{5}^{2}$ & 084 & 054 & 084 & 054 & 084 & 054 \\
\hline$V_{6}$ & 1025 & 019 & 025 & 019 & 023 & 019 \\
\hline
\end{tabular}

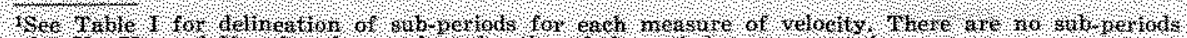

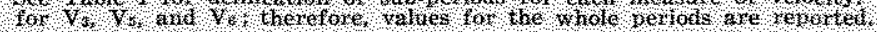
Bewho $11 / 190$.

of percent changes in velocity relative to the trend growth rate.

Table III presents the various standard deviations of quarterly percent changes in the seven measures of velocity. According to the data, $V_{1}$ and $V_{6}$ have the smallest quarterly variability for the whole period. When the time horizon is extended to four and to eight quarters, the differences in variability among the seven measures of velocity are narrowed considerably. Over a four-quarter period $V_{1}$ and $V_{6}$ have the smallest average quarterly variability, and over an eight-quarter period $V_{\text {rabs, }} V_{1}$, and $V_{i}$ have the smallest average quarterly variability.

When consideration is given to the breaks in the trend growth rates (Table III), $V_{6}$ has the smallest short-run quarterly variability in sub-period $I$, and $V_{m b}, V_{1}$, and $V_{2}$ have the smallest in sub-period II. When quarterly percent changes are averaged over four quarters, $V_{b}$ has the smallest short-run variability in sub-period I, while in sub-period II, $V_{m b}$ and $V_{1}$ have the smallest. Averaging over eight quarters the smallest variability occurs for $V_{1}$ and $V_{6}$ in sub-period $I$, and for $V_{m b}, V_{1}, V_{2}$, and $V_{0}$ in sub-period II.

\section{Conclusions From Analysis of Velocity}

As mentioned earlier, it has frequently been asserted that the monetary aggregate with the smallest variability in its income velocity can be expected to forecast nominal GNP with the smallest error. Based on this assertion, the analysis of longrun variability of velocity suggests that $\mathbf{M}_{6}$; (total liquid assets) would forecast nominal GNP with the smallest error. Its velocity had virtually no trend in the period from 1952 to 1973 and no break in trend. Moreover, in all but one instance, $V_{6}$ has the smallest longrun variability. On the other hand, $\mathrm{M}_{1}$ and the monetary base would be expected to forecast nominal GNP with the largest error, since a substantial break occurred in their trends of velocity and they have the largest long-run variability in velocity. These conclusions, however, are misleading because of trend movements in several of the measures of velocity.

The analysis of the relative short-run variability in the seven measures of velocity, which adjusts for trend, indicates that over intervals of time relevant for economic stabilization, $\mathrm{M}_{i j}$ could be expected to yield consistently smaller errors in forecasting nominal GNP. In all cases but one, $V_{6}$ had the smallest shortrun variability. There is, however, little superiority of $\mathrm{M}_{63}$ over monetary base, $\mathrm{M}_{1}$, and $\mathrm{M}_{2}{ }^{3}$

BEvidence from the period 1952 to 1973 does not support Friedman's contention that at the present time $\mathrm{M}_{2}$ is preferred over $\mathrm{M}_{1}$ for economic stabilization. A change in the trend growth of both $V_{1}$ and $V_{2}$ occurred, but at different dates. In addition, the magnitude of the two changes were almost identical - a reduction of 1.4 percentage points for $v_{1}$ and 1,2 percentage points for $V_{2}$. It thus appears that the trend

rable 11

Short Run Variability of Velocity

(Sicndord Deviotion of Percent Changet in Velocity of Annual Rates)

\begin{tabular}{|c|c|c|c|c|c|c|c|c|c|}
\hline \multirow[b]{3}{*}{ velocity } & \multicolumn{3}{|c|}{1952,01973} & \multicolumn{3}{|c|}{ Sub period One' } & \multicolumn{3}{|c|}{ Sub-perbod Iwo? } \\
\hline & \multirow{2}{*}{$\begin{array}{l}\text { Quarlerly } \\
\text { Change }\end{array}$} & \multicolumn{2}{|c|}{ Averoge evarrerly Chonge } & \multirow{2}{*}{$\begin{array}{l}\text { Guarterly } \\
\text { Ghonge }\end{array}$} & \multicolumn{2}{|c|}{ Ayerage Quorterly Ghonge } & \multirow{2}{*}{$\begin{array}{l}\text { Quorterly } \\
\text { Qhorge }\end{array}$} & \multicolumn{2}{|c|}{ Average Qugterly Change } \\
\hline & & 4 quarters & 8 quarters & & 4 ovariers & 8 anorters & & 4, guorrers & Savorters \\
\hline van & $4.0 \%$ & $2,4 \%$ & $12 \%$ & $4 \%$ & $24 \%$ & $16 \%$ & $32 \%$ & $1.6 \%$ & $12 \%$ \\
\hline $\mathbf{v}_{1}$ & 3.6 & 20 & 12 & 40 & 2,4 & 12 & 3,2 & 16 & 12 \\
\hline$v_{2}$ & 4.4 & 28 & 16 & 52 & 3.6 & 2.0 & 32 & 20 & 12 \\
\hline$y_{3}^{2}$ & 4.0 & 24 & 16 & 40 & 2,4 & 1.6 & 40 & 2, & 16 \\
\hline$y_{4}$ & 48 & 32 & 20 & 52 & 36 & 2.0 & 4,0 & 28 & 18 \\
\hline$y^{2}$ & 14 & 28 & 20 & 4, & 28 & 20 & 44 & 28 & 20 \\
\hline$v_{6}$ & 3.6 & 2.0 & 12 & 3.6 & 20 & 12 & 3.6 & 2.0 & 12 \\
\hline
\end{tabular}

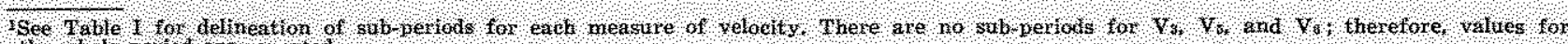
the whole pertod are teparted.

$2+1011195$ 


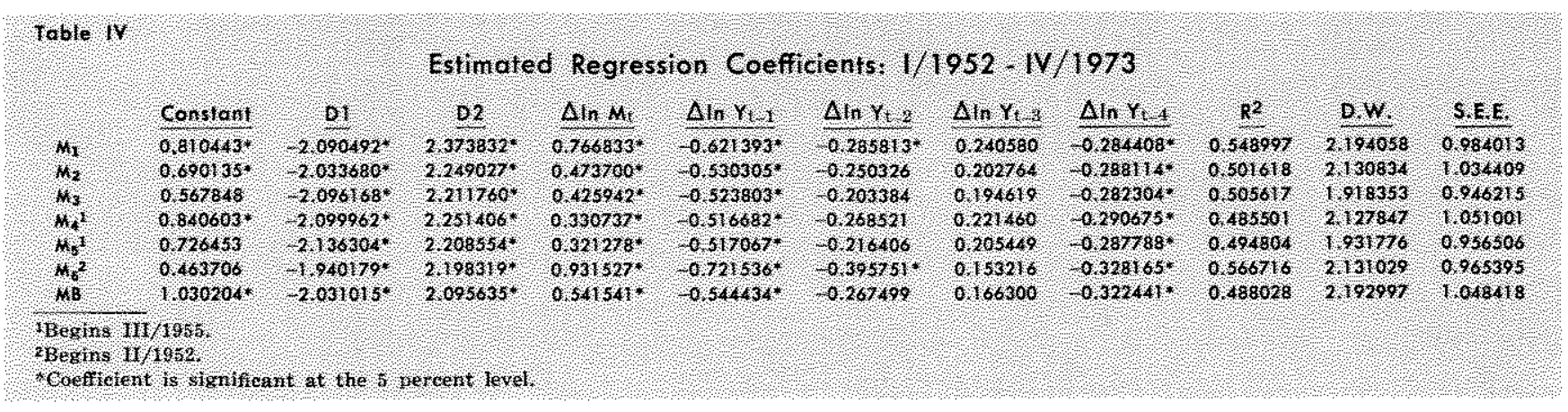

At best, the indirect velocity approach is a shortcut to the forecasting question. While the analysis of long-run variability of velocity suggests that $\mathrm{M}_{6}$ would forecast nominal GNP with the smallest error, the analysis of short-run variability of velocity is inconclusive in this regard.

One additional point should be made-relative stability of velocity does not necessarily indicate that one monetary aggregate will forecast nominal GNP with a smaller error than will any other aggregate because high variability does not preclude predictability. Therefore, the direct forecasting approach would produce a more definitive test for selecting the appropriate monetary aggregate for economic stabilization.

\section{DIRECT FORECASTING APPROACH}

A monetary model of nominal income (GNP) determination is used to ascertain the relative forecasting ability of the seven monetary aggregates. The model was spelled out in detail in a previous article. ${ }^{4}$ The basic feature of the model is that the change in the rate of change in nominal spending by households and business firms for newly produced goods and services is postulated to respond to the discrepancy between the rates of change in actual and desired nominal money balances. It is therefore distinguished from the more familiar post-Keynesian types of forecasting models. The empirical form of the model con-

of $V_{2}$ is subject to as much uncertainty as that of $V_{1}$. The aralysis of short-run changes in velocity also does not confirm Friedman's contention that $V_{y}$ is more stable than $V_{1}$.

\&eonall C. Andersen, "A Monetary Model of Nominal Income Determination," Review (June 1975). The model was developed using $M_{1}$ and $M_{2}$. When applying it to $M_{3}$ through $M_{6}$, it is postulated that in each case the change in the rate of change in spending responds to the discrepancy between the rate of change in actual and desired stocks. Other models could be developed based on different speciffoations and could be used to forecast nominal income. Thus, the forecasting results reported here are applicable only to the model presented.

sists of three equations, which are presented in Exhibit II.

Exhibitl

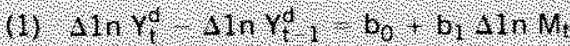

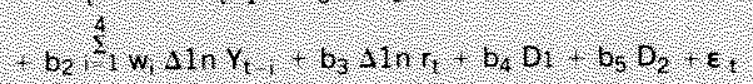

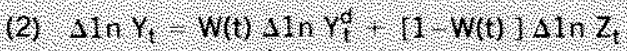

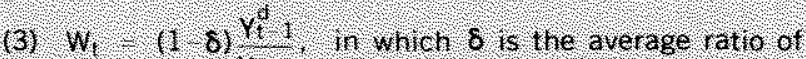
Y.t 1 inports to Y. 2 in sample period.

4in 40,010

๑)

sin $M$

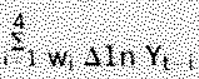

An ri

$\ln \mathrm{Y}_{\mathrm{t}}$

0

$\mathrm{D}_{2}$

6

$\sin 2$

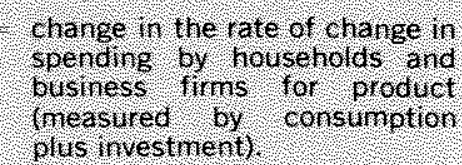

- response of spending by households and business hits to average rate of change in technical etficiency of the payments system

- hate of change in a monetary aggregate

tweighted sum of past rates of change in hominal income theasured by hominal GNP)

ate of change in nominal short tem interest late Ineas. wed by the 4.6 nonths com merelal paper ratel.

Trale of change in hominal income (measured by rominal GNPI

zero-one dumny variable tor najor strikes. One In 1959 Il. $1964 . \mathrm{V}$ ard $1070 \mathrm{~W}$

4 zero one dumny variable one in quarter following a major strike.

a random error term

rale of change in government spending olus foreign spending on oomestic produdt heasured by National Incone accounts for total government purchases of goods and services plus exports) 
Table $V$

Simulation

Period Beginning

$\frac{1 Q}{1962}$

1962
1963
1964

1965

1900

1967

1968

1969

1970

1971

1972

1973

1974

RMSE

Maximum Error

$\begin{array}{lr} & M \\ 1962 & 1.67 \\ 1963 & 4.78 \\ 1964 & 1.89 \\ 1965 & 1.89 \\ 1966 & 2.25 \\ 1967 & 7.28 \\ 1968 & 3.13 \\ 1969 & 2.20 \\ 1970 & 4.58 \\ 1971 & 2.08 \\ 1972 & -3.68 \\ 1973 & -1.56 \\ \text { RMSE } & 3.50 \\ \text { Maximum Error } & 7.28\end{array}$

$\begin{array}{lr} & \frac{M_{1}}{1962} \\ 1963 & 3.13 \\ 1964 & 7.59 \\ 1965 & 1.95 \\ 1966 & 5.86 \\ 1967 & 5.95 \\ 1968 & 9.43 \\ 1969 & 5.01 \\ 1970 & 5.30 \\ 1971 & 3.63 \\ 1972 & 0.04 \\ \text { RMSE } & -3.52 \\ \text { Maximum Error } & 5.30 \\ & 9.43\end{array}$

Maximum Error

Percent Errors in Simulated Level of GNP

Fourth Quarter

$\begin{array}{rr}\frac{\mathrm{M}_{1}}{-1.68 \%} & \frac{\mathrm{M}_{2}}{2.37 \%} \\ 3.41 & 2.12 \\ -0.09 & -1.74 \\ 2.66 & 3.88 \\ -1.20 & -1.37 \\ 4.30 & 2.84 \\ 1.92 & -0.61 \\ 0.49 & -1.92 \\ 1.51 & 0.10 \\ 3.26 & 3.66 \\ -1.45 & -2.25 \\ -1.93 & -2.42 \\ 1.13 & 0.96 \\ 2.24 & 2.28 \\ 4.30 & 3.88\end{array}$

$\frac{M_{3}}{0.27 \%}$
0.96
-3.05
2.57
-3.02
1.35
-1.85
-2.82
-1.08
3.97
-2.64
-2.98
0.18
3.69
3.97

$\frac{M_{4}}{3.60 \%}$
2.62
-1.49
3.51
-2.00
2.38
-1.26
-3.46
0.58
2.59
-2.80
-1.65
1.55
2.45
3.60

$\frac{M_{5}}{1.08 \%}$
1.19
-2.91
2.37
-0.09
0.99
-2.16
-3.56
-0.54
2.53
-3.23
-2.47
0.74
2.38
-3.89

$\frac{M_{6}}{0.19 \%}$
2.94
-2.11
0.26
-4.45
0.65
-0.50
-2.48
-0.74
2.91
-0.54
-0.90
1.22
1.99
-4.45

$\frac{M B}{-0.92 \%}$
0.36
-2.23
0.49
-2.02
1.13
-1.07
-1.14
0.36
1.82
-2.72
-2.15
1.91
1.59
-2.72

Eighth Quarter

$\frac{M_{2}}{5.59}$
0.96
0.50
1.99
0.23
2.01
-2.21
-1.54
4.23
1.79
-5.36
-2.25
2.92
5.59

$$
0.73
$$

$-1.90$

$-2.39$

$-3.37$

$-3.21$

$-1.22$

$-4.40$

$-3.63$

3.70

2.59

$-6.34$

$-3.86$

3.43

$-6.34$

$\frac{M_{4}}{8.50}$
1.98

1.98

0.41

0.53

$-0.80$

0.70

$-4.38$

$-2.13$

3.77

0.10

$\begin{array}{r}-1.16 \\ \hline\end{array}$

3.48

8.50

$\frac{M_{5}}{2.54}$

$\frac{M_{6}}{25}$

$\frac{M B}{-0.62}$

$-1.46$

$-2.32$

$-3.85$

$-3.56$

$-1.96$

$-5.38$

$-3.38$

2.51

$-0.02$

$-6.63$

$-2.96$

3.47

Twelfth Quarter

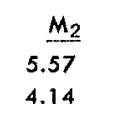

$\underline{M_{3}}$

-1.50
-0.56

$-6.65$

$-1.59$

$-5.39$

$-3.31$

$-5.00$

1.95

2.45

$-0.05$

$-7.21$

4.01

$-7.21$

$$
\text { er }
$$

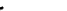

$\begin{array}{rr}3.25 & -0.62 \\ -1.43 & -1.70 \\ -4.33 & -2.70 \\ -2.72 & -2.53 \\ 0.26 & -1.72 \\ -2.76 & -0.19 \\ -2.26 & -2.00 \\ 2.43 & 0.15 \\ 2.42 & 2.28 \\ -1.81 & -0.81 \\ -0.25 & -5.29 \\ 2.36 & -0.95 \\ -4.33 & 2.21\end{array}$

\section{Forecasting Procelure}

The parameters of equation (1) are estimated by ordinary least squares using quarterly data." Seven

5The interest rate was excluded. It is assumed that the indirect interest rate influence of changes in an aggregate on spending by households and business firms is reflected in the estimated parameters.

$\begin{array}{rr}\frac{M_{4}}{9.94} & \frac{M_{5}}{14} \\ 5.01 & -0.14 \\ -2.10 & -6.80 \\ 2.67 & -2.10 \\ -2.05 & -6.01 \\ -2.27 & -4.77 \\ -3.09 & -5.01 \\ 1.80 & 0.94 \\ 1.25 & -0.02 \\ -1.88 & -2.94 \\ -5.10 & -7.25 \\ 4.14 & 4.23 \\ 9.94 & -7.25\end{array}$

$$
\begin{array}{r}
M B \\
-2.66 \\
-2.08 \\
-5.32 \\
-1.76 \\
-2.75 \\
-0.72 \\
-0.78 \\
1.88 \\
-0.41 \\
-0.00 \\
-4.52 \\
2.77 \\
-5.32
\end{array}
$$

sets of equations were estimated, one for each monetary aggregate." For each monetary aggregate, the parameters of equation (1) are estimated for the

\footnotetext{
6The inclusion of the monetary base is justified by the identity $\mathrm{M}_{\mathrm{t}}=\mathrm{m}_{\mathrm{t}} \mathrm{MB}_{\mathrm{t}}$, in which $\mathrm{m}_{\mathrm{t}}$ is the appropriate multiplier.
} 
period from first quarter 1952 to fourth quarter 1961, except for $M_{3}$ and $M_{5}$ which begin in third quarter 1955 and $M_{6}$ which begins in second quater 1952. The sample period is then extended by four quarters and the parameters are re-estimated. This procedure continues through the terminating quarter which is fourth quarter 1973. The parameter estimates for the longest sample period are reported in Table IV. ${ }^{7}$

Next, for each monetary aggregate, ex ante (beyond each sample period) dynamic simulations are conducted using the complete model. Actual values in the post-sample period of the exogenous variables - each monetary aggregate, total government spending on goods and services, and exports - are used. The lagged $\Delta \mathrm{ln} \mathrm{Y}$ terms are generated intemally. Of interest to this study are the simulated quarterly levels of nominal GNP. Although these simulations are not forecasts in the strict sense, they may be viewed as forecasts with knowledge of future movements in the three exogenous variables.

\section{Torecasting Results}

These simulation exercises are used to ascertain the comparative forecasting capabilities of the seven monetary aggregates using the specified model. Forecasts of nominal GNP using each monetary aggregate are developed for successive post-sample periods of four, eight, and twelve quarters. Forecast errors - the difference between predicted and actual quarterly levels of nominal GNP as a percent of actual GNP - are

TThe parameter estimates for all of the sarmple periods are available on request. The procedure of lengthening the sample period differs from another frequently ised procedmre of maintaining a moving, fixed lergth sample period. The argument for using this latter procedure is that it better captures changes it structure, that is, basic changes in the regression coefficients. "lhe procedire used in this study is instified on the basis of tests which rejected the structural change hypothesis for equation (1) using $\mathrm{M}_{1}$ and $\mathrm{M}_{2}$. See Andersen

"A Monetary Model of Nominal Income Detemination." calculated for the fourth, eighth, and twelfth quarters of each post-sample period. These errors are reported in Table $\mathrm{V}$.

Two types of forecast error are calculated for each monetary aggregate. One is the root-mean-squared error (RMSE) for each of the three sets of terminal quarters. This measure provides an indication of the average forecasting ability of each aggregate; the one with the smallest RMSE forecasts best, on average, the level of GNP. The other measure is the maximum error within each of the three sets of forecasts. The aggregate with the smallest maximum error is best if avoidance of large forecasting errors is desired. These two measures are presented in Table $\mathrm{V}$.

On the basis of these simulations of the specified model, the monetary base appears to forecast the level of nominal GNP the best. Its RMSE is the smallest for each of the three simulated terminal quarters. In addition, it has the smallest maximum forecast error for the fourth and the twelf th quarters, and it has the second smallest maximum error for the eighth quarter.

\section{CONCLUSTONS}

This paper investigated one criterion for choosing a monetary aggregate for economic stabilization the aggregate which forecasts nominal GNP with the smallest error. For time periods of general interest, the indirect income velocity approach produced rather inconclusive evidence regarding the choice of a mon. etary aggregate. Although this approach would reject $\mathrm{M}_{3}, \mathrm{M}_{4}$, and $\mathrm{M}_{5,}$, there was little basis for choosing among the other four aggregates. The direct forecasting approach based on the specified model, however, found that the monetary base forecasts the level of nominal GNP with the smallest root-mean-squared error in every case and with the smallest-maximum error in two out of three cases.

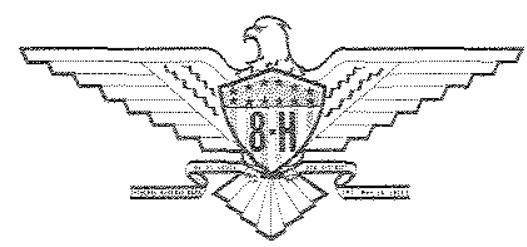

